\title{
Characterisation of polysaccharides from the fern Platycerium bifurcatum with expected biological activity.
}

\author{
Omeje E.O., *Adikwu M.U , Esimone C.O. , Obonga W.O., \\ Okide G.B. and Eberendu O. C.
}

\author{
Department of Pharmaceutical and Medicinal Chemistry \\ Faculty of Pharmaceutical Sciences \\ University of Nigeria, Nsukka
}

\begin{abstract}
Platycerium bifurcatum, a widely growing fern was collected and the phytochemical analysis of the powdered plant showed that polysaccharides were present in appreciable quantity. It was found that $4.0 \%$ sodium hydroxide solution was required for optimum extraction and then precipitated using $99.0 \%$ ethanol in an overall yield of $4.85 \%$. By appropriate phytochemical analysis of the polysaccharides, it was found to be of very high purity- approximately $90.0 \%$. The chromatography of the hydrolysed polysaccharide established presence of mainly $\mathrm{D}$-galactose units, using the retardation factor values $\left(\mathrm{R}_{\mathrm{fvalues}}\right)$ of various sugars as primary standard and reference. The solubility profile indicates that the polysaccharide was insoluble in organic solvents, sparingly soluble in water and acids, and soluble in alkaline medium. The crystalline compound was found to melt at a temperature range of $165-171^{\circ} \mathrm{C}$ and decomposes at a temperature range of $185-200^{\circ} \mathrm{c}$. Other parameters for complete characterisation were established for the extract. The extract was found to be free from foreign matter, and microorganisms and heavy metals found were of acceptable concentration.
\end{abstract}

Keywords: Characterisation, Polysaccharide, fern, Platycerium bifurcatum, Chromatography.

\section{Introduction}

Polysaccharides are component of almost all living organisms. They are most abundant in the higher order of land plants and in seaweeds where they constitute approximately $75.0 \%$ the dry weight. They are abundant in fungi and in the exoskeletons of insects and crustaceans. They are important constituents of the capsules of micro organisms and of the slimes which are produced by numerous organisms. They are significant components of cartilage of animal joint fluids, of fluid multitudinous places, usually in large amounts but often in small quantities (1). Physiologically, polysaccharides perform diverse roles in plants (2), animals and micro organisms. First, they serve as structural material in plant and in most organisms as fuel reserves for metabolism. They serve structurally in the exoskeletons on insects and crustaceans and protectively in the capsular material of 
certain. As surface material, they partially protect tissues from desiccation and as gums they are exuded from plants to seal and protect wounds. As thickeners, they serve in mechanical roles in animals and as specific substances; they are of importance in blood group specificity and in other immunological reactions. Usually, higher animals do not depend greatly on polysaccharides for structural support but the lower animals use chitin as their principal frame substance. Polysaccharides in such sites as the respiratory, gastrointestinal and genitourinary tracts perform such common function as protection and lubrication. Generally, polysaccharides are not found in isolated pure condition but are deposited with other materials and may be inlaid and overlaid with other polysaccharides, proteins, fats, and many other biological substances (3).

Polysaccharides or polymerized saccharides are condensation polymers in which monosaccharides or their derivates (such as amino sugars) have been glycosidically joined (with the elimination of water) according to the empirical equation.

$$
\mathrm{nC}_{6} \mathrm{H}_{12} \mathrm{O}_{6} \quad\left\{\mathrm{C}_{6} \mathrm{H}_{10} \mathrm{O}_{5}\right\}+(\mathrm{n}-\mathrm{I}) \mathrm{H}_{2} \mathrm{O} \ldots \ldots \ldots \ldots \ldots \ldots \text { (1) }
$$

Therefore, on complete acid hydrolysis, polysaccharides yield only simple sugars or their derivatives. Although low molecular weight polysaccharides could be made by direct condensation in the laboratory, natural polysaccharides seem to be evolved by other routes. The term polysaccharide is limited to condensation polymers comprising ten or more monosaccharide residues as opposed to oligosaccharide usually containing two to nine sugar monomers. The size of polysaccharide molecules vary, however, most natural polysaccharides are of high molecular weight. Polysaccharides are also called glycans and thus, the term homoand heteroglycans represent polysaccharides containing similar and varied types of sugar units respectively. Polysaccharides may be linear as in structural cellulose or branched as in those, which serve as food reserves, albeit starch consists of mixture of linear and branched polysaccharides with the branched type predominating. These branched polysaccharides are easily soluble in water and possess very high thickening powers. Linear molecules on the other are insoluble or sparingly soluble excellent structural materials because they pack closely and form numerous intermolecular secondary valence attachments. Plant gums contain polysaccharides. Polysaccharides constitute a structurally diverse class of biological macromolecules with a wide range of physicochemical properties, which are the basis for their different applications in the field of pharmacy and medicine. The importance of various polysaccharide hydrocolloids for pharmaceutical purposes has a long historical background and increased considerably during the last decade (4). This is not only the case for polysaccharides used as excipients essential for specific drug formulations but also for a series of carbohydrate polymers which have proven to be most useful as physiologically active drugs. They fill diverse roles such as in wound treatment, drug delivery, in 
cancer therapy and in diagnosis, prevention and treatment of bacterial and viral diseases. The use of polysaccharide hydrocolloids in antitussives formulations such as cough drops, cough syrups, and cough lozenges is well documented (4). In this regard, they act as anti-inflammatory agents consequently reducing the dry cough. Polysaccharide hydrocolloids are used in treatment for the common constipation. Usually, all these high-fiber and high polysaccharide hydrocolloid preparations have to be used with the adequate amount of liquid; otherwise a reverse effect will be possible (5). Topical application of these polysaccharides may have an indirect or direct effect on the area of application. Semisolid systems fulfill a special topical need by being able to cling to the surface of application. They have been utilized for the production of lipid-cling to the surface of application. They have been utilized for the production of lipid-free ointments, pastes, and creams and as emulsifiers. In addition to its use in laxative preparations agar finds use in such other pharmaceutical preparations as tablet coatings, and granulating agents. Agar has medical application as an inhibitor of blood clothing. For a substance to be effective as in blood clothing, it must be water soluble, have high molecular weight, possesses a sulphate anion or other acid group of similar strength (6). Polysaccharides have found diverse uses in textile, confectionery, paper, printing, food and chemical industries (7).

The need to source, extract and characterize this polysaccharide from the fern is the basis of this work. This fern, platycerium bifurcatum (fam: Polypodiaceae, Cav.) of the order; filicates is found in all tropical and sub-tropical regions of Africa, Asia and South America. They are found growing widely on the backs of woody trees in southern Nigeria (8). Physico-chemical constants and compositions are thus determined by standard techniques.

\section{Materials and methods}

The following materials were used as purchased; ethanol $90.0 \%$, sodium hydroxide $(\mathrm{NaOH})$, Sodium Borohydride (May and Baker), acetic acid, ethylacetate, pyridine and aniline phthalate (Merck, Damsdat, Germany). Distilled water (from Science and Training Center, University of Nigeria Nsukka).

\section{Collection and Identification}

The fern plant was collected from the back of palm trees located within the vicinity of the University of Nigeria and identified by Mr. A.O. Ozioko of the Department of botany of the same University.

\section{Methods}

Following collection and identification, the fronds of this plant were washed sundried to a constant weight and subsequently pulverized in a hammer mill. The 
resulting powder was passed through a No 20 sieve. Phytochemical analysis was carried out using aliquots $(0.5 \mathrm{~g})$ of the crude powdered material. The polysaccharide was then extracted using 100.0 grams of the powder in 1 litre of $4 \%$ $\mathrm{NaOH}$ then filtered and dried at a regulated oven temperature of $40-60^{\circ} \mathrm{C}$ to a constant weight. The yield was determined and subsequently the physiochemical analysis of the pure polysaccharide extract carried out. The solubility profile was also established. Thin layer chromatography was used to identify the polysaccharide present by co-spotting with some pure samples of sugars and comparing their retardation factor (RF) values. Further characterization was done by determining its melting point using the melting point apparatus.

Phytochemical Analysis of Crude Plant Material.

Phytochemical tests were carried out on the crude powered plant material using standard procedures (9).

\section{Extraction of Polysaccharides}

Exactly $100 \mathrm{~g}$ of powdered platycerium bifurcatum was macerated with 1 litre of 4.0 $\%$ sodium hydroxide solution containing $10 \mathrm{~g}$ sodium borohydride. The mixture was put in a rotary shaker for 24 hours at $40^{\circ} \mathrm{C}$ and afterwards, filtered with a stabilized neutral $\mathrm{PH}$. The polysaccharide was precipitated in excess $99 \%$ ethanol, the supernatant decanted, then filtered and washed with ethanol and then air-dried to obtain the pure dry polysaccharide. The yield was determined by differential weighing. All previous physiochemical studies were repeated with the extracted polysaccharide. The next was to determine the solubility profiles of the extract. This was done by attempting to dissolve $0.1 \mathrm{~g}$ of the extracted under varying conditions of agitation and temperature in divers solvent. About $1.0 \mathrm{~g}$ of the extracted polysaccharide was hydrolysed with $50 \mathrm{ml}$ of I N sulphuric acid at $100^{\circ} \mathrm{C}$ for 2 hours on a water bath (10). The resulting solution was co-chromatographed on a $20 \mathrm{~cm} \times 20$ $\mathrm{cm}$ prepared cellulose thin-layer plates (11), with reference sugar including glucose, galactose, xylose, fructose and sucrose all of D-series and L-arabinose in an established solvent system of ethylacetate-pyridine- water in 2:1:2 ratio. The developed chromatogram was observed and distances traveled by respective spots recorded for computation of RF values. The corresponding $\mathrm{R}_{\mathrm{f}}$ values were calculated using the formula,

$\underline{\mathrm{R}}_{\mathrm{f}}=$ Distance of compound from origin

Distance of solvent from origin

The distance of solvent from origin was $15 \mathrm{~cm}$ and that for Glucose, sucrose, polysaccharide sample, Arabinose, Xylose, and Galactose being 9.6, 9.0, 8.8, 10.8, $12.3,12.0$ and 8.8 respectively all in centimeters; these showed that Galactose had the same RF value with the extracted polysaccharide in the solvent system. Finally, 
the melting point range was found to be $165-171^{\circ} \mathrm{C}$ determined using the melting point apparatus. Further descriptive tests such as the microscopy, loss on drying, residue on ignition, heavy metals, microbial load, foreign matter, identity and purity were carried out on the extract following standard procedures (12-15). This was to completely characterize the Polysaccharide.

\section{Result and Discussion}

The process of collection of plant material and subsequent characterization are summarised in figure 1 while result with an aniline phthalate spray reagent and heat is show in figure 2 . This made the developed spots visible. The physiochemical studies on the crude plant powder and extract are depicted in tables 1 and 2 respectively. Table 3 shows the yield of polysaccharide from the plant while the solubility profile is depicted in table 4 . Finally, the determined $R_{f}$ values are show in table 5. The descriptive features of the extract are shown in table 6 . The necessity to carry out these series of characterization cannot be overemphasized. First, the constituent, purity and exaction efficiency can easily be established. As can be seen from tables 1 , and 2 alkaloids were absent which agrees with research of finding of workers of plants of the fern family (10). High content of carbohydrates proteins and saponins as shown in table I is expected, while glycosides, flavonoids, tannins, and reducing sugars were all present in moderate amount with only steroidal aglycone in low amount. The entire composition was changed in the extract since only glycoside, reducing sugar and carbohydrates were present with carbohydrates being in appreciably high amount. One would expect that besides the potential food values of this polysaccharide, its pharmacological activities cannot be overruled. The contrast between results obtained as show in tablesland 3 indicates the efficiency of the extraction process especially with regards to purity. Further characterization of this extract is therefore recommended. Furthermore, the established melting point range of $165-171^{\circ} \mathrm{C}$ for the extract is in agreement with the range expected for D-galactose the chief constituent of the hydrolysed polysaccharide depending on the impurity level (16). The solubility profile also established the presence of polysaccharides since as expected; they were insoluble in organic solvent, sparingly soluble in acids and water but highly soluble in alkaline solution. The use of sodium hydroxide for the extraction is therefore understandable and recommended. The identical Rf values of the hydrolysed extraction extract and galactose establishes galactose as the chief constituent of the polysaccharide. In conclusion, a polysaccharide consisting chiefly of D-galactose units has been extracted from the fern, Platycerium bifurcatum. The galactan perhaps is a linear polysaccharide judging from the ease of hydrolysis. Beside the food value of the extract, it may likely possess a pharmacological activity, the confirmation which the authors consider a research worthy of further investigation. The authors also recommend future workers to be able to establish the molecular 
weight, configuration, viscosity of its solution and any other know polysaccharide parameter necessary for complete characterization and classification.

Fig. 1: The Flow Diagram of Procedure for Characterization

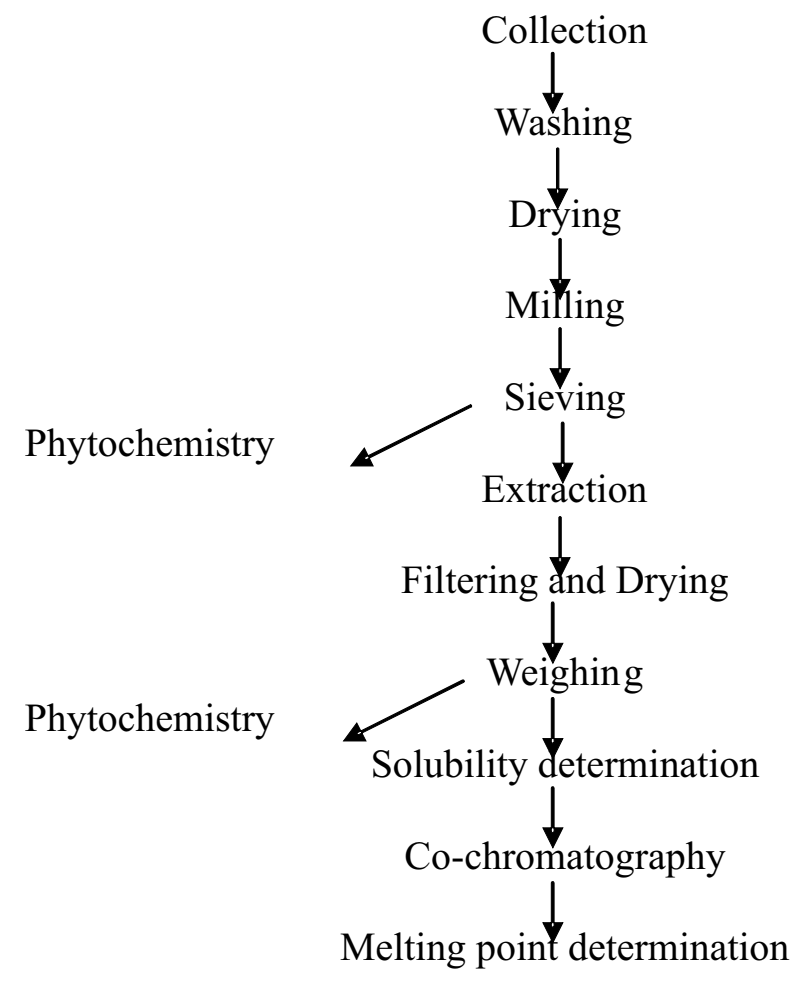


Fig.2: The Developed Sample Chromatogram*

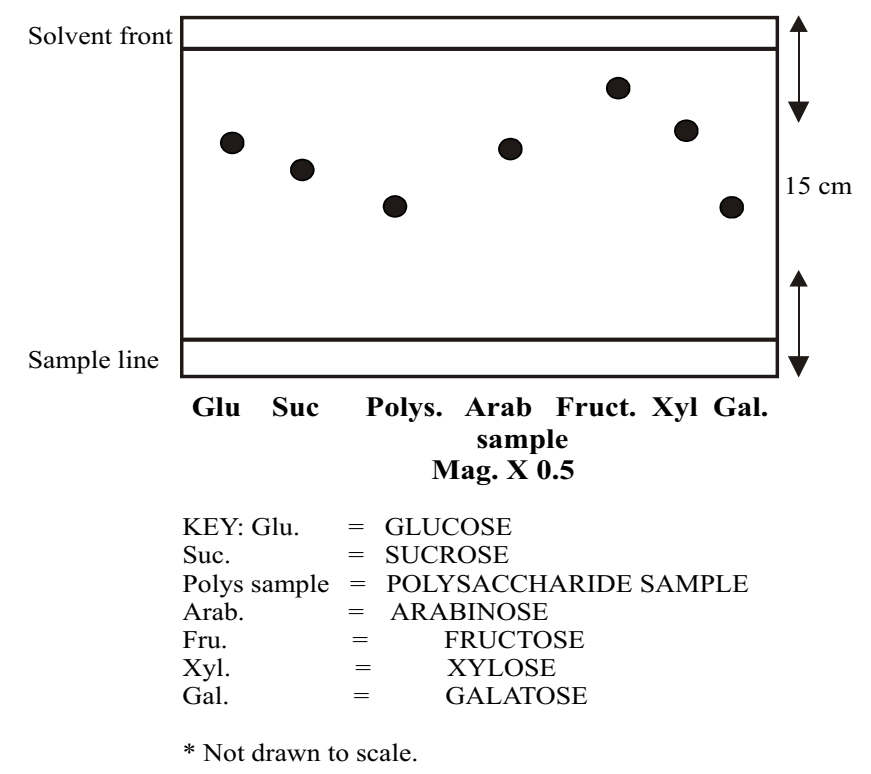

Table1: Phytochemical studies on the crude plant powder.

\begin{tabular}{|c|c|c|}
\hline $\mathrm{S} / \mathrm{NO}$ & Constituent & Presence \\
\hline 1 & Alkaloids & - \\
\hline 2 & Glycosides & ++ \\
\hline 3 & Flavonoids & ++ \\
\hline 4 & Tannins & ++ \\
\hline 5 & Saponins & +++ \\
\hline 6 & Steroidal Aglycone & + \\
\hline 7 & Proteins & +++ \\
\hline 8 & Reducing Sugar & ++ \\
\hline 9 & Carbohydrate & ++ \\
\hline Key: & \multicolumn{2}{|c|}{$\begin{array}{l}\text { ++ Present in moderate quantity } \\
\text { - Absent }\end{array}$} \\
\hline $\mathrm{S} / \mathrm{NO}$ & Constituent & Presence \\
\hline 1 & Alkaloids & - \\
\hline 2 & Glycosides & + \\
\hline 3 & Flavonoids & - \\
\hline 4 & Tannins & - \\
\hline 5 & Saponins & - \\
\hline 6 & Steroidal Aglycone & - \\
\hline 7 & Proteins & - \\
\hline 8 & Reducing Sugar & + \\
\hline 9 & Carbohydrate & +++ \\
\hline
\end{tabular}


Table 3: Yield of polysaccharides from the plant.

\begin{tabular}{lc}
\hline Weight of powdered plant & $100.0 \mathrm{~g}$ \\
Weight of extract & $4.85 \mathrm{~g}$ \\
Percentage yield & $4.85 \mathrm{~g}$ \\
\hline
\end{tabular}

Table 4: Solubility Profile of Polysaccharide Extract.

\begin{tabular}{|l|l|l|l|l|}
\hline S/N & Solvent & Highly Soluble & $\begin{array}{l}\text { Sparingly } \\
\text { Soluble }\end{array}$ & Insoluble \\
\hline 1. & Water & - & + & - \\
2. & Acetic acid & - & + & - \\
3. & Hydrochloric acid & - & + & - \\
4. & Sulphuric acid & - & + & - \\
5. & Nitric acid & - & + & - \\
6. & Sodium hydroxide & + & - & - \\
7. & Ammoniac Solution & + & - & - \\
8. & Potassium hydroxide & + & - & - \\
9. & Ethanol & - & - & + \\
10. & Ethyl acetate & - & - & + \\
11. & Butanol & - & - & + \\
12. & Methanol & - & - & + \\
13. & Isopropanol & - & - & + \\
14. & Chloroform & - & - & + \\
15. & Carbon tetrachloride & - & - & + \\
& & & & \\
& & & & \\
\hline
\end{tabular}

Table 5: Determined $\mathbf{R}_{\mathrm{f}}$ values of Reference Sugars and Extract.

\begin{tabular}{llcc}
\hline S/No & Saccharide & Distance traveled $(\mathrm{cm})$ & RF \\
\hline 1. & Glucose & 9.6 & 0.64 \\
2. & Sucrose & 9.0 & 0.60 \\
3. & Extract & 8.8 & 0.59 \\
4. & Arabinose & 10.8 & 0.72 \\
5. & Fructose & 12.5 & 0.82 \\
6. & Xylose & 12.0 & 0.80 \\
7. & Galactose & 8.8 & 0.59 \\
\hline
\end{tabular}




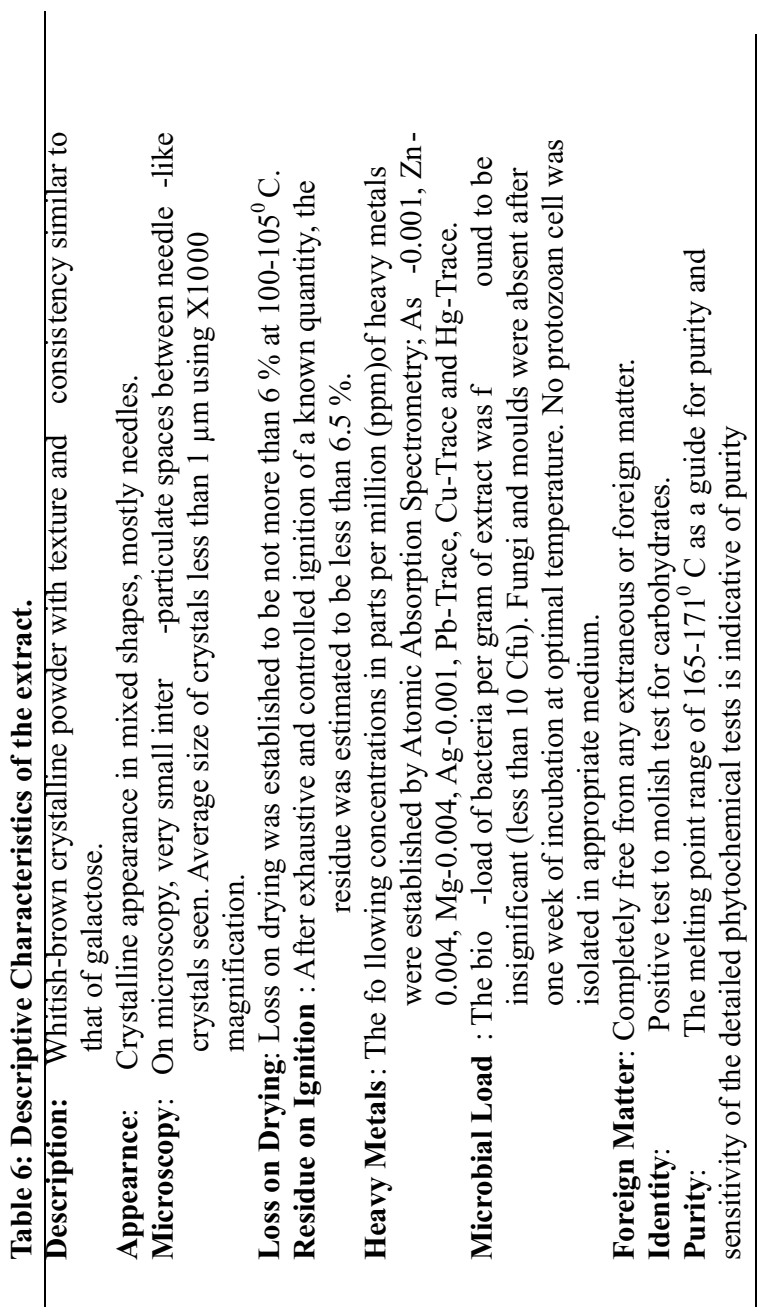




\section{References:}

1. Whistler, R.L. (1953) Polysaccharide Chemistry, Academic press inc., p 1.

2. Atkins E.D.T. Mackie w. (1985) plant cell walls: Morphology, Biosynthesis and Growth in "polysaccharides: topics in structure and morphology. The Macmillan press Ltd.

Houndnills Basingstoken Hampshire RG21 2xs p73-83.

3. Whistler R L (1965), Methods in Carbohydrate chemistry. Vol. 5, Aca. Press Inc.332.

4. Franc, G.(1989), Polysaccharide in Pharmacy: Current Application and future concepts: Plant medica 55,493.

5. Franc, G. (1984),Polysaccharide Hydrocolloids in medicine. Euromed,2,69-73.

6. Whistler R.L., (1953) Polysaccharide Chemistry Academic press inc. 217.

7. Kunle O.O, Pharmaceutical grade starch and some of its potential sources in Nigeria, Journal of Phytomedicine and Therapeutics 7 (1\&2) 2002, 1-17.

8. Aspinall G.O; (1970), Polysaccharide, Pergamam Press, N.Y;15

9. Evans W.C. (1998) Trease and Evans, Pharmacognosy Bailliere Tindal, London.

10. Agarwal s.p. (1973) Polysaccharide of Bombax flower, Planta medica. 21298

11. Macek k; (1981). The Task of thin-layer Chromatography, Mack pub. Co., 133.

12. Hess, H., Dnusel, F. and Mullen, K. (1969). Methods of counting microorganism. Pharm. Acta. Helv. 44: 174-176.

13. British Pharmacopoeia, 2001 Vol 2, A136.

14. British Pharmacopoeia, 2001 Vol 2, A189.

15. British Pharmacopoeia, 2001 Vol 2, A420-421.

16. Whistler R.L., (1953), Polysaccharides chemistry, Academic press inc; 215. 